\title{
Characteristics, course and outcomes of children admitted to a paediatric intensive care unit after cardiac arrest
}

\author{
J Appiah, ${ }^{1,2,3}$ MB ChB, MWACP, MPhil, Cert Crit Care (Paed); S Salie, ${ }^{1,2}$ MB ChB, DCH, FCPaed, Cert Crit Care (Paed); \\ A Argent, ${ }^{1,2} \mathrm{MB}$ ChB, MMed(Paed), MD(Paed), DCH (SA), FCPaed (SA); B Morrow, ${ }^{2} \mathrm{PhD}, \mathrm{BSc}$ (Physiotherapy) \\ ${ }^{1}$ Paediatric Intensive Care Unit, Red Cross War Memorial Children's Hospital, Cape Town, South Africa \\ ${ }^{2}$ Department of Paediatrics and Child Health, University of Cape Town, Cape Town, South Africa \\ ${ }^{3}$ Paediatric Intensive Care Unit, Department of Child Health, Komfo Anokye Teaching Hospital, Kumasi, Ghana
}

Corresponding author: J Appiah (adabiea@gmail.com)

\begin{abstract}
Background. Cardiac arrest is a potentially devastating event, associated with death or severe neurological complications in survivors. There is little evidence on paediatric cardiac arrest prevalence, characteristics and outcomes in South Africa (SA).

Objective. To describe the characteristics, course and outcomes of children admitted to an SA paediatric intensive care unit (PICU) following cardiac arrest.

Methods. Retrospective descriptive study of routinely collected data (January 2010 - December 2011).

Results. Of 2501 PICU admissions, 110 (4.4\%) had preceding cardiac arrest. The median (interquartile range (IQR)) age of children was 7.2 (2.5 - 21.6) months. In-hospital arrests accounted for $80.6 \%$ of the events. The most common primary diagnostic categories were respiratory (29.1\%), cardiovascular (21.4\%) and gastrointestinal (21.4\%). Twenty-four patients (23.3\%) arrested during endotracheal intubation. Cardiopulmonary resuscitation (CPR) was applied for a median (IQR) of 10 (5 - 20) minutes. Duration of CPR for non-survivors and survivors was 17.5 (10 - 30$)$ v. $10(5-15)$ minutes $(p=0.006)$. PICU mortality was $38.8 \%$, with half of the deaths occurring within 24 hours of admission. The standardised mortality ratio was 0.7. The median (IQR) length of stay in the PICU and hospital was $3(1-8)$ and 27 (9 -52) days, respectively. No independent predictors of mortality were identified. Thirty-nine surviving patients $(76.5 \%)$ had normal neurological function or mild disability at follow-up after hospital discharge. Six (11.8\%) survived with severe disability.

Conclusion. Mortality was lower than predicted in children admitted to the PICU following cardiac arrest. The majority of survivors had good neurological outcomes.

Keywords. Pediatric, cardiac arrest, cardiopulmonary resuscitation, pulseless electrical activity, ventricular tachycardia, pediatric intensive care unit, in-hospital cardiac arrest, out-of-hospital cardiac arrest
\end{abstract}

S Afr J Crit Care 2018;34(2):58-64. DOI:10.7196/SAJCC.201.v34i2.355

Cardiac arrest is defined as the cessation of functional mechanical activity of the heart, determined clinically by absent central pulses, unresponsiveness and apnoea. ${ }^{[1,2]}$ Absence of blood flow leads to non-perfusion of vital organs, including the brain, kidneys and the heart muscle. ${ }^{[3-5]}$ Cardiac arrest is a potentially devastating event, associated with death or severe neurological complications in survivors. It may occur both in previously healthy children and in children with underlying diseases or abnormalities. The last 15 years have seen an improvement in epidemiological data collection of cardiac arrest, ${ }^{[6,7]}$ and the publication of management guidelines has contributed to improvements in outcome. ${ }^{[8-10]}$ There are, however, little published data on paediatric cardiac arrest from low-income countries.

The true incidence of paediatric cardiac arrest is unknown, but outof-hospital cardiac arrest (OHCA) events are estimated at 9 per 100000 person years, whereas arrest within intensive care units is thought to occur 0.94 times per 100 admissions. ${ }^{[11-13]}$ A large proportion (40 $55 \%$ ) of OHCAs in children occur in infants compared with other age categories. ${ }^{[12,14-16]}$ In children, respiratory and cardiovascular failure are the major causes of cardiac arrest, but cardiac arrhythmias may not be as uncommon as was previously thought. ${ }^{[17]}$

The understanding of factors influencing, and the sequence of events leading to, cardiac arrest is thought to have contributed to improved survival. ${ }^{[18]}$ Early recognition of patients at risk of arrest, timeous intervention and instituting effective cardiopulmonary resuscitation (CPR) that involves ventilation, chest compression and pharmacological agents, with ongoing monitoring and management following return of spontaneous circulation (ROSC), may all contribute to improved survival following cardiac arrest. ${ }^{[19,20]}$

Although the process of cardiac arrest and resuscitation is a continuum, it may be seen to consist of four phases: prearrest; no flow; low flow, and ROSC. ${ }^{[21,22]}$ The prearrest phase may be associated with respiratory failure or shock states, which can result in asphyxia or ischaemia and so lead to inadequate delivery of substrate for cellular metabolism. This phase, if untreated, leads to established cardiac arrest, with the cessation of mechanical activity of the heart, absent pulses and a no-flow state. The low-flow phase ensues when CPR is instituted. The main goal of intervention at this stage is to optimise cerebral, coronary and other vital organ perfusion. Effective, uninterrupted chest compression at this stage is key to a successful outcome. ${ }^{[23]}$ Abnormalities in oxygenation and ventilation are also common during the initial hours after paediatric cardiac arrest. ${ }^{[21]}$ It therefore makes clinical sense to optimise oxygenation and haemodynamic stability ${ }^{[24,25]}$ with ventilator support, fluids and inotropic support as required, to ensure improved survival of patients following cardiac arrest. ${ }^{[26]}$ 
The main objectives of this study were: to describe the characteristics, course and outcomes of patients admitted to the paediatric intensive care unit (PICU) following cardiac arrest; to compare the outcomes of patients following in-hospital cardiac arrest (IHCA) and OHCA, and to review factors associated with outcomes based on the Utstein-style reporting of cardiac arrest. ${ }^{[27]}$

\section{Methods \\ Study setting and population}

This retrospective study was conducted at the PICU of the Red Cross War Memorial Children's Hospital (RCWMCH) in Cape Town, South Africa (SA). This is a teaching hospital with 290 paediatric beds. The multidisciplinary PICU has 22 functional beds and accepts patients from birth to 13 years of age from general paediatric wards, the emergency and trauma department, surgical wards and operating theatres within the hospital, and also serves as a referral centre for patients from elsewhere in the Western Cape province.

Although there is no dedicated response team in the event of cardiac arrest or potential collapse within the hospital, an intercom system is used to alert medical staff to the event. Initial resuscitation is performed by ward personnel, with assistance from those who respond to the call. There is no clear protocolised guide for terminating CPR; this decision is taken by the resuscitation team when they think treatment is futile, which is usually after $20-30$ minutes. In cases of OHCA, the patient may be resuscitated by bystanders or, if available, trained emergency medical personnel.

The study population consisted of all children $<14$ years of age who were admitted to the PICU between 01 January 2010 and 31 December 2011 following a documented cardiac arrest outside of the PICU, with CPR and ROSC. The patients were identified through review of the electronic PICU database.

As a general policy, the standard management of post-arrest syndrome and its complications was based on published recommendations, including targeting normal temperature or mild hypothermia, a blood glucose level of $8-10 \mathrm{mmol} / \mathrm{L}$, ventilation support and early goaldirected haemodynamic stabilisation. ${ }^{[26,28]}$ Lung-protective ventilation strategies were used to target normal oxygenation. ${ }^{[22]}$

\section{Data collection}

Data were extracted from medical folders and entered into a case record form modified for IHCA or OHCA using the Utstein-style guidelines. ${ }^{[27,29]}$ Information collected included: patient demographics; Paediatric Index of Mortality (PIM2) score on PICU admission; ${ }^{[30]}$ cardiac arrest aetiology (according to primary diagnostic category ${ }^{[27]}$ ) and location (IHCA or OHCA); duration of CPR; advanced life-support medications used; initial cardiac rhythm; monitoring at the time of arrest; laboratory blood tests, and PICU management (including inotropic support and mechanical ventilation).

The primary outcome was PICU mortality. Secondary outcomes were: level of consciousness at PICU discharge according to the 'alert, voice, pain, unresponsive' (AVPU) scale; ${ }^{[31]}$ hospital survival; length of stay in hospital and the PICU, and neurological outcome 3 - 6 months after PICU discharge, measured using the Paediatric Overall Performance Category (POPC) scale, as per standard practice at a follow-up clinic. ${ }^{[32]}$ For the purposes of this study, prolonged CPR was defined as intervention continuing for $>30$ minutes, which is beyond the usual norm. For patients who had multiple arrests, data from the first arrest were used. Definitions of other terms used in this paper are presented in Table 1.

Approval for the study was obtained from the institutional Human Research Ethics committee (ref. no. 344/2012). The requirement for written informed consent was waived owing to the retrospective nature of the study.

\section{Data analysis}

Data were captured in Epi Info ${ }^{\mathrm{TM}}$ 7.0.9.7 software and exported to a spreadsheet. Statistica version 11 (Statsoft Inc., USA) was used to analyse the data. The Shapiro-Wilk test was used to test the distribution of continuous data. Numerical variables are presented as medians and interquartile ranges (IQRs) throughout, as appropriate for nonparametric data. The Mann-Whitney $U$ test was used to compare continuous variables between survivors and non-survivors of cardiac arrest events. Pearson's $\chi$-squared test ( $95 \%$ confidence interval) was used to test for associations of categorical variables. Kruskal-Wallis analysis of variance was used to determine the impact of CPR duration on POPC-scale outcome classifications. Factors significantly associated with PICU mortality on univariate analysis $(p<0.05)$ were entered into a stepwise backward logistic regression analysis model to determine independent predictors of the outcome. A significance level of $p<0.05$ was used.

\section{Results}

A total of 45417 patients were admitted to the hospital over the period of study, of whom 2501 (5.5\%) required PICU admission. Of the PICU patients, 110 (4.4\%) were admitted following cardiac arrest, representing a hospital incidence of 2.4 per 1000 hospital admissions and 44.0 per 1000 PICU admissions. Data were available for 103 of the 110 cardiac

\section{Table 1. Definitions of terms used}

\begin{tabular}{ll}
\hline Term & Definition \\
\hline Cardiac arrest & Cessation of functional mechanical activity of the heart, with absent central pulses, unresponsiveness and apnoea ${ }^{[1]}$ \\
Apnoea & Cessation of breathing for $>20$ seconds \\
Primary diagnosis & The main condition treated or the most clinically severe or life-threatening condition that was deemed likely to have led to \\
& cardiac arrest \\
Bradycardia & Heart rate $<80$ beats per minute in the newborn to 2 years of age, or $<60$ beats per minute in children over 2 years of age \\
Tachycardia & Heart rate $>160$ beats per minute in the newborn to 2 years of age or more than twice normal for age \\
Hyperthermia & Documented axillary temperature $>38.5^{\circ} \mathrm{C}$ \\
Hypothermia & Documented axillary temperature $<35.5{ }^{\circ} \mathrm{C}$ \\
Shock & A combination of any of the following: abnormal mental status; weak, thready pulses; prolonged capillary refill time and \\
& cold extremities; low blood pressure \\
Acute kidney injury & Acute decline in renal function measured by decreases in urine output and serum creatinine clearance post arrest episode, \\
& with specific pRIFLE scoring criteria to categorise the injury
\end{tabular}




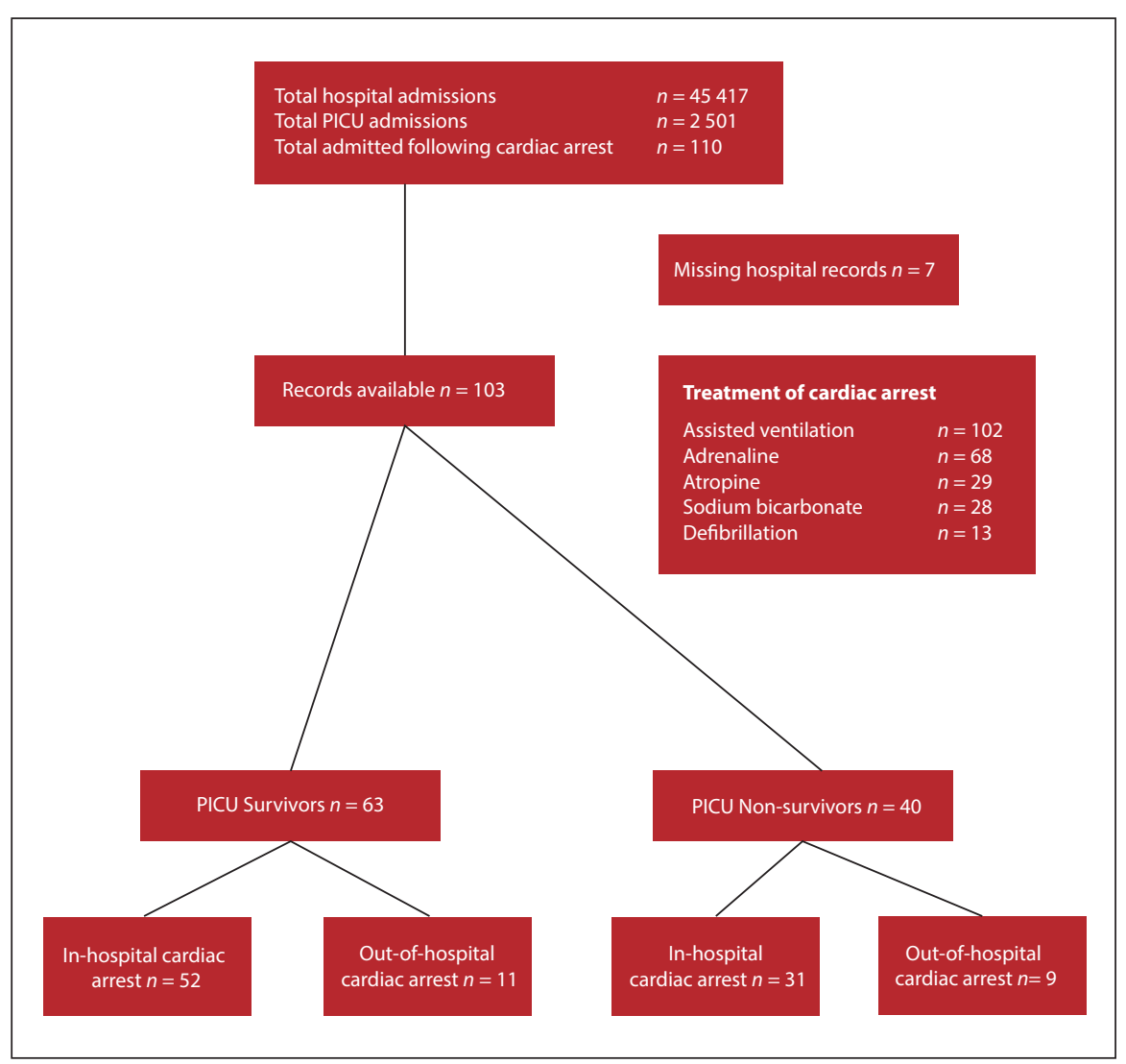

Fig. 1. Participant enrolment flow chart, arrest management and survival outcomes. (PICU = paediatric intensive care unit).

arrest patients and were subsequently included in the study (Fig. 1).

\section{Patient characteristics}

Characteristics of the included patients are presented in Table 2. The majority of participants $(n=30 ; 29.1 \%)$ had primary respiratory disease underlying their arrest, most commonly associated with acute lower respiratory infections $(n=21 ; 70.0 \%)$.

Twenty-nine cardiac arrests (28.2\%) resulted from progressive deterioration in patients with a diagnosed medical condition; four $(3.9 \%)$ events were expected, and in nine $(8.7 \%)$ cases the underlying conditions prior to arrest were not documented. Of the 28 arrests during a procedure, $24(85.7 \%)$ occurred during endotracheal intubation, two (7.1\%) occurred intraoperatively, one (3.6\%) during cardiac catheterisation and one (3.6\%) during insertion of a central venous line. Of the 24 arrests that occurred during endotracheal intubation, 16 (66.7\%) occurred in the emergency department, wards or other hospitals and eight (33.3\%) occurred in theatre. Supervision by senior medical staff was documented for only two (12.5\%) of 16 patients who arrested while undergoing intubation in the emergency department. The majority $(80 \%)$ of patients who were in shock during intubation received inotropic support prior to arresting.

\section{Location of arrest}

IHCA occurred in 83 (80.6\%) of the patients, whereas OHCA was documented in 20 (19.4\%) cases (Table 3). 'Other' IHCA events included six (7.2\%) cases that occurred during interhospital transfer in the ambulance.

\section{Physiological and laboratory findings}

Less than a fifth of the patients $(n=19 ; 18.4 \%)$ had a documented cardiac rhythm recorded at arrest: four $(21.1 \%)$ had pulseless electrical activity, asystole was recorded in ten (52.6\%) cases and five patients (26.3\%) had ventricular tachycardia or fibrillation. Temperature at arrest was recorded for 17 patients (16.5\%), of whom 14 (82.4\%) were hypothermic and two (11.8\%) had hyperthermia; one patient (4.8\%) in this group was normothermic.

The first blood chemistry results after the arrest and ROSC are presented in Table 4.

\section{Management of arrest}

The median duration of resuscitation (and associated IQR) was 10 (5 - 20) minutes. Prolonged CPR ( $>30$ minutes) was performed on five patients (4.9\%). Fig. 1 and Table 5 summarise peri-arrest management interventions. A third of the patients $(n=34$; $33.0 \%)$ did not receive any adrenaline during the resuscitation, whereas $44(42.7 \%)$ received up to three doses of adrenaline and 24 (23.3\%) received more than three doses. At least one defibrillation was performed in 13 (13.7\%) of the 95 patients treated this way. One (1\%) patient was cardioverted for supraventricular tachycardia following CPR.

\section{Post-arrest management}

The majority of patients ( $n=98 ; 95.1 \%)$ received ventilator support after ROSC. Only one patient received non-invasive continuous positive airway pressure, with the remainder all being intubated and ventilated mechanically. The median duration of mechanical ventilation (and associated IQR) was $2(0-5)$ days. Close to three-quarters of the patients $(n=74 ; 71.8 \%)$ received inotropes during their PICU admission.

\section{Post-arrest organ complications}

Circulatory failure was the most common complication following cardiac arrest, with 71 patients (68.9\%) clinically shocked following the arrest. Neurological complications were recorded in $25(24.3 \%)$ cases, with seizures $(n=18)$ representing $72.0 \%$, persistent loss of consciousness $(n=4) 16.0 \%$ and focal signs $(n=3) 12.0 \%$. A total of 25 patients (24.3\%) developed acute kidney injury according to the so-called 'paediatric risk, injury, failure, loss, end stage renal disease' (pRIFLE) criteria. Some patients had more than one complication.

\section{Outcomes}

The median lengths of stay in the PICU and hospital (with associated IQRs) were $3(1-8)$ and $27(9-52)$ days, respectively. More than half of the patients $(n=63 ; 61.2 \%)$ survived to PICU discharge - 52 (82.5\%) following IHCA and 11 (17.5\%) following OHCA $(p=0.7)$ (Table 6). Of the 40 PICU deaths, 20 (50\%) occurred within 24 hours of arrest. The standardised mortality rate (actual/ mean predicted mortality using the PIM2 score) was 0.7. Factors associated with PICU mortality on univariate analysis included: underlying neurological conditions; duration of resuscitation; PIM2 score; post-arrest $\mathrm{pH}$, chloride, creatinine and lactate; receipt of inotropes in the PICU, and neurological sequelae post arrest (Tables 5 and 6). On multiple regression analysis, none of these variables were found to be independently associated with PICU mortality. 
Table 2. Characteristics of the study population post cardiac arrest $(N=103)$

\begin{tabular}{|c|c|}
\hline Characteristics & $n(\%)$ \\
\hline Male & $60(58.3)$ \\
\hline Age (months), median (IQR) & $7.2(2.5-21.6)$ \\
\hline \multicolumn{2}{|l|}{ Age (months) } \\
\hline$<1$ & $12(11.6)$ \\
\hline $1-12$ & $52(50.4)$ \\
\hline $12-36$ & $22(21.4)$ \\
\hline $36-72$ & $10(9.7)$ \\
\hline$>72$ & $7(6.8)$ \\
\hline Weight (kg), median (IQR) & $5.8(3.7-10.0)$ \\
\hline PIM2 score, median (IQR) & $0.54(0.28-0.85)$ \\
\hline \multicolumn{2}{|l|}{ Primary diagnosis } \\
\hline Neurological & $9(8.7)$ \\
\hline Tumour & $3(33.3)$ \\
\hline Hydrocephalus & $1(11.1)$ \\
\hline Meningitis & $1(11.1)$ \\
\hline Subdural haemorrhage & $1(11.1)$ \\
\hline Cerebral abscess & $1(11.1)$ \\
\hline Encephalitis & $1(11.1)$ \\
\hline Tuberculous meningitis & $1(11.1)$ \\
\hline Respiratory & $30(29.1)$ \\
\hline Acute lower respiratory tract infection & $21(70.0)$ \\
\hline Tuberculosis & $1(3.3)$ \\
\hline Foreign-body aspiration & $2(6.7)$ \\
\hline Aspiration & $4(13.3)$ \\
\hline Tension pneumothorax & $1(3.3)$ \\
\hline Pulmonary haemorrhage & $1(3.3)$ \\
\hline Cardiovascular & $22(21.4)$ \\
\hline Congenital heart disease & $16(72.2)$ \\
\hline Dilated cardiomyopathy and myocarditis & $6(27.3)$ \\
\hline Gastrointestinal & $22(21.4)$ \\
\hline Acute diarrhoeal disease & $14(63.6)$ \\
\hline Necrotising enterocolitis & $3(8.7)$ \\
\hline Intestinal perforation & $2(9.1)$ \\
\hline Bowel obstruction & $1(4.5)$ \\
\hline Gastric haemorrhage & $1(4.5)$ \\
\hline Protein energy malnutrition & $1(4.5)$ \\
\hline Trauma & $4(3.9)$ \\
\hline Abdominal & $1(25.0)$ \\
\hline Non-accidental injury & $1(25.0)$ \\
\hline Pedestrian motor vehicle accident & $1(25.0)$ \\
\hline Burns & $1(25.0)$ \\
\hline Other & $16(15.5)$ \\
\hline Drowning & $5(31.3)$ \\
\hline Sepsis & $5(31.3)$ \\
\hline Haematologic/oncologic & $3(18.8)$ \\
\hline Poisoning/drug overdose & $2(12.5)$ \\
\hline Disseminated tuberculosis & $1(6.3)$ \\
\hline $\mathrm{IQR}=$ interquartile range. & \\
\hline
\end{tabular}

Of the 63 patients who were discharged from the PICU, four died in the wards. Two of these deaths were documented as being unrelated to the cardiac arrest, whereas no association was documented for the remaining two deaths.

Assessment of level of consciousness on PICU discharge was conducted using the AVPU criteria: 54 of the 63 PICU survivors (85.7\%) were discharged from the PICU alert, one (1.6\%) was responsive to voice, four $(6.3 \%)$ to pain; one $(1.6 \%)$ was unresponsive, and the
Table 3. Locations of arrest event

\begin{tabular}{ll}
\hline Arrest location & $\boldsymbol{n}(\%)$ \\
\hline Out of hospital & $20(19.4)$ \\
At home & $10(50.0)$ \\
Public place & $10(50.0)$ \\
In hospital & $83(80.6)$ \\
Emergency unit & $18(21.7)$ \\
Wards & $41(49.4)$ \\
Operating theatre & $8(9.6)$ \\
Other & $16(19.3)$
\end{tabular}

Table 4. First blood biochemistry results following return of spontaneous circulation $(N=103)$

\begin{tabular}{ll}
\hline Parameter & Median $(\mathrm{IQR})$ \\
\hline Blood glucose $(\mathrm{mmol} / \mathrm{L})$ & $6.3(4.3-13.5)$ \\
$\mathrm{pH}$ & $7.16(6.99-7.30)$ \\
Sodium $(\mathrm{mmol} / \mathrm{L})$ & $138.0(134.0-142.0)$ \\
Potassium $(\mathrm{mmol} / \mathrm{L})$ & $4.1(3.6-5.1)$ \\
Chloride $(\mathrm{mmol} / \mathrm{L})$ & $106.0(101.0-110.0)$ \\
Ionised calcium $(\mathrm{mmol} / \mathrm{L})$ & $1.26(1.12-1.60)$ \\
Creatinine $(\mu \mathrm{mol} / \mathrm{L})$ & $60.0(36.5-88.0)$ \\
Lactate $(\mathrm{mmol} / \mathrm{L})$ & $5.4(2.4-11.6)$ \\
IQR $=$ interquartile range. &
\end{tabular}

level of consciousness was not documented in three cases. Of the 59 patients who were discharged from hospital, 51 (86.4\%) were assessed neurologically and developmentally $3-6$ months post discharge. According to the POPC scale, 32 (62.7\%) were classified as normal and seven (13.7\%) displayed mild disability. Moderate and severe disability was recorded in six patients (11.8\%) in each of the respective groups. None were in a persistent vegetative state. Duration of resuscitation had no effect on POPC outcome $(p=0.7)$.

\section{Discussion}

This retrospective study of PICU admissions following cardiac arrest in a single SA tertiary centre showed a prevalence of 2.4 per 1000 hospital admissions over the period under review. This figure is likely to be an underestimate of the true prevalence of cardiac arrest in the hospital, as we were unable to collect data on patients who did not survive to ROSC and PICU admission. Further research is warranted to determine overall prevalence and outcomes of cardiac arrest. Arrest episodes occurred predominantly in infants younger than 1 year, similar to other reports. ${ }^{[3,36]}$

Respiratory, cardiac and gastrointestinal disorders were the most common primary diagnostic conditions related to cardiac arrest. We were unable to classify the precipitating cause of arrest into hypoxia/ asphyxia or circulatory shock, ${ }^{[22,37]}$ owing to the retrospective nature of this study and inadequate reporting. Our data showed that underlying respiratory and gastrointestinal diseases were more likely to be of recent onset (mainly acute lower respiratory tract infections and acute diarrhoeal disease), while cardiac disease was generally related to chronic comorbid conditions (congenital heart disease). Although not confirmed on the basis of our data, acute respiratory tract infections and other respiration-related causes were pathophysiologically most likely associated with hypoxia, while gastrointestinal diseases such as acute diarrhoeal diseases most likely precipitated circulatory failure or hypovolaemic shock. ${ }^{[38,39]}$

Two previous studies have evaluated IHCA: one in the form of a prospective study conducted in Brazil (a middle-income country with comparable characteristics to $\mathrm{SA}){ }^{[37]}$ and the other being a retrospective 
Table 5. Peri- and post-arrest management, monitoring and complications in survivors v. non-survivors

\begin{tabular}{|c|c|c|c|}
\hline Parameter & $\begin{array}{l}\text { PICU deaths } \\
(N=40), n(\%)\end{array}$ & $\begin{array}{l}\text { PICU survivors } \\
(N=63), n(\%) \\
\end{array}$ & $p$-value \\
\hline \multicolumn{4}{|l|}{ Peri-arrest management } \\
\hline Duration of resuscitation (min) & $17.5(10-30)$ & $10(5-15)$ & 0.006 \\
\hline \multicolumn{4}{|l|}{ Number of adrenaline doses } \\
\hline 0 & $12(30.0)$ & $22(34.9)$ & 0.6 \\
\hline 1 & $7(17.5)$ & $14(22.2)$ & 0.7 \\
\hline 2 & $7(17.5)$ & $5(7.9)$ & 0.2 \\
\hline 3 & $5(12.5)$ & $6(9.5)$ & 0.6 \\
\hline 4 & $3(7.5)$ & $3(4.8)$ & 0.9 \\
\hline 5 & $2(5.0)$ & $3(4.8)$ & 0.7 \\
\hline 6 & $4(10)$ & $9(14.3)$ & 0.7 \\
\hline \multicolumn{4}{|l|}{ Number of defibrillation events ( $N=95)$} \\
\hline 0 & $35(94.5)$ & $47(81.0)$ & 0.2 \\
\hline 1 & $1(2.7)$ & $2(3.4)$ & 0.7 \\
\hline 2 & $0(0.0)$ & $1(1.7)$ & 0.8 \\
\hline 3 & $0(0.0)$ & $1(1.7)$ & 0.8 \\
\hline 6 & $1(2.7)$ & $7(12.1)$ & 0.2 \\
\hline \multicolumn{4}{|l|}{ Peri-arrest monitoring } \\
\hline \multicolumn{4}{|l|}{ ECG $(N=19)$} \\
\hline Pulseless electrical activity & $2(40)$ & $2(14.3)$ & 0.96 \\
\hline Asystole & $2(40)$ & $8(57.1)$ & 0.3 \\
\hline Ventricular tachycardia/fibrillation & $1(20)$ & $4(26.7)$ & 0.7 \\
\hline \multicolumn{4}{|l|}{ Respiratory rate $(N=42)$} \\
\hline Arrest/apnoea & $12(100)$ & $26(86.7)$ & 0.5 \\
\hline Tachypnoea & 0 & $4(13.3)$ & 0.3 \\
\hline \multicolumn{4}{|l|}{ Blood pressure $(N=43)$} \\
\hline Unrecordable & $7(36.8)$ & $7(29.2)$ & 0.5 \\
\hline Hypotensive & $12(63.2)$ & $17(70.8)$ & 0.7 \\
\hline \multicolumn{4}{|l|}{ Temperature $(N=17)$} \\
\hline Hypothermic & $7(77.8)$ & $7(87.5)$ & 0.4 \\
\hline Normothermic & 0 & $1(12.5)$ & 0.8 \\
\hline Hyperthermic & $2(22.2)$ & 0 & 0.3 \\
\hline \multicolumn{4}{|l|}{ Post-arrest management } \\
\hline Inotropic support & $34(85)$ & $40(63.5)$ & 0.03 \\
\hline Invasive mechanical ventilation & $40(100)$ & $57(90.5)$ & 0.1 \\
\hline \multicolumn{4}{|l|}{ Post-arrest blood biochemistry $(N=103)^{*}$} \\
\hline $\mathrm{pH}$ & $7.07(6.88-7.20)$ & $7.22(7.09-7.36)$ & 0.001 \\
\hline Sodium $(\mathrm{mmol} / \mathrm{L})$ & $139.0(134.0-146.0)$ & $137.0(133.0-140.0)$ & 0.08 \\
\hline Chloride (mmol/L) & $109.0(103.0 .-118.0)$ & $104.0(101.0-129.0)$ & 0.03 \\
\hline Magnesium (mmol/L) & $1.1(1.0-1.5)$ & $1.1(0.9-1.3)$ & 0.71 \\
\hline Calcium $(\mathrm{mmol} / \mathrm{L})$ & $1.3(1.1-1.5)$ & $1.2(1.1-2.0)$ & 0.64 \\
\hline Urea $(\mathrm{mmol} / \mathrm{L})$ & $5.7(3.2-7.3)$ & $5.5(3.8-7.3)$ & 0.89 \\
\hline Creatinine $(\mu \mathrm{mol} / \mathrm{L})$ & $79.0(45.0-118.5)$ & $54.0(34.0-72.0)$ & 0.01 \\
\hline Lactate $(\mathrm{mmol} / \mathrm{L})$ & $11.5(5.2-15.7)$ & $3.2(1.4-6.8)$ & $<0.0001$ \\
\hline \multicolumn{4}{|l|}{ Post-arrest complications } \\
\hline Neurological & $15(37.5)$ & $10(15.9)$ & 0.02 \\
\hline Acute kidney injury & $13(32.5)$ & $12(19.0)$ & 0.2 \\
\hline Shock & $32(80.0)$ & $39(61.9)$ & 0.09 \\
\hline
\end{tabular}

study from Finland (a high-income country). ${ }^{[27]}$ Although limited to IHCA, both these studies collected similar data using Utstein-style reporting. In both studies, the model of care and personnel managing patients with cardiac arrest were similar to our setting. We found a $57.3 \%$ survival-to-hospital-discharge rate. This is similar to the findings of the Finnish study, ${ }^{[27]}$ but differs considerably from the rate (25.3\%) reported in the Brazilian study. ${ }^{[37]}$ For both the Finnish and Brazilian studies, the most common precipitating cause of arrest was cardiac in nature $(71 \%$ and $61 \%$, respectively), while in our study respiratory and cardiac conditions accounted for $29.1 \%$ and $21.4 \%$ of arrests, respectively. Although cardiac arrhythmias, ventricular tachycardia and fibrillation were documented in $4.8 \%(n=5)$ of our cases, we were unable to ascertain whether these were the primary underlying causes of cardiac arrest in these patients. Notably, initial electrocardiographic 
Table 6. Demographic data and cardiac arrest aetiology of survivors v. non-survivors

\begin{tabular}{|c|c|c|c|}
\hline Variable & $\begin{array}{l}\text { PICU deaths } \\
(N=40), n(\%)\end{array}$ & $\begin{array}{l}\text { PICU survivors } \\
(N=63), n(\%) \\
\end{array}$ & $p$-value \\
\hline Age (months), median (IQR) & $9.0(2.4-26.6)$ & $6.6(2.7-16.9)$ & 0.38 \\
\hline Weight (kg), median (IQR) & $6.4(4.1-12.0)$ & $5.5(3.3-9.5)$ & 0.21 \\
\hline Male & $26(65.0)$ & $34(54.8)$ & 0.3 \\
\hline PIM2 score, median (IQR) & $0.83(0.52-0.97)$ & $0.41(0.23-0.68)$ & $<0.0001$ \\
\hline \multicolumn{4}{|l|}{ Underlying condition category } \\
\hline Neurological & $8(20.0)$ & $1(1.6)$ & 0.002 \\
\hline Respiratory & $10(25.0)$ & $18(28.6)$ & 0.4 \\
\hline Cardiovascular & $5(12.5)$ & $17(27.0)$ & 0.1 \\
\hline Gastrointestinal & $10(25.0)$ & $12(19.0)$ & 0.3 \\
\hline Trauma & $3(7.5)$ & $1(1.6)$ & 0.3 \\
\hline \multicolumn{4}{|l|}{ Location of arrest } \\
\hline OHCA & $9(22.5)$ & $11(17.5)$ & \multirow{2}{*}{0.7} \\
\hline IHCA & $31(77.5)$ & $52(82.5)$ & \\
\hline
\end{tabular}

monitoring was extremely poor in our study, potentially introducing bias into our results, and these findings therefore need to be confirmed in prospective studies.

Our results showed that a clinically relevant proportion $(23.3 \%)$ of cardiac arrest episodes occurred during endotracheal intubation procedures, mostly emergency intubations in the emergency department and hospital wards. Considering that most of these patients were likely to have been in peri-arrest status at the time of intubation, consequently with a high predicted risk of cardiac arrest, it is concerning that the majority of these endotracheal intubation procedures were not overseen by senior staff. It is therefore strongly recommended that emergency endotracheal intubation be considered a high-risk procedure, and that senior staff should be present to supervise whenever possible.

$\mathrm{CPR}$ is the mainstay of treatment for cardiac arrest. Effective CPR, with adequate depth of chest compression and rate, alternating with ventilation and oxygen, has significantly improved the outcome of paediatric cardiac arrest. ${ }^{[40]}$ There is, however, insufficient evidence to recommend when to terminate CPR, although it has previously been shown that a short duration of CPR is the best prognostic indicator of survival in children. ${ }^{[27]}$ However, in a study that included $>3000$ children, Matos et al. ${ }^{[41]}$ suggested that more patients may survive following prolonged CPR than previously thought. There does, however, remain the concern that prolonged CPR may lead to poor neurological outcome in survivors. ${ }^{[41]}$ Five of the patients in our study (5\%) had prolonged CPR, showing that in our setting, providers occasionally continued beyond the conventional period for terminating CPR, although this was not the norm. The reasons for prolonged resuscitation were not indicated in the patient hospital records. Although there was an association between duration of CPR and PICU mortality on univariate analysis, no association was found between duration of resuscitation and neurological outcome using the POPC scale. Furthermore, on multiple regression analysis, duration of resuscitation was no longer identified as a predictive factor for PICU mortality. Considering that poor neurological outcomes were recorded in only a small number of surviving patients in our study, further large-sample prospective studies are warranted to confirm our findings. As also seen in another study, ${ }^{[5]}$ we found that shock was the most prevalent complication following an arrest, with acute kidney impairment and neurological impairment present in equal proportions.
A large proportion of the patients in our study who had successful CPR with ROSC survived to hospital discharge with reasonable neurological outcomes. Our observed hospital mortality rate of $42.7 \%(n=44)$ was comparable to the $43.2 \%$ reported by Suominen et al. ${ }^{[27]}$ and the standardised mortality rate of 0.7 in our cohort indicates better-thanpredicted PICU survival based on the PIM2 score at admission. The nature of this study did not allow for estimation of change in neurological status from pre- to post-arrest status, and this requires further investigation. Approximately three-quarters $(n=39 ; 76.5 \%)$ of the patients who survived to hospital discharge and were available for follow-up had good neurological outcomes, with scores indicating normal function or only mild disability. Only six survivors (11.8\%) had severe disability. These findings are almost identical to those of a large cohort study, which reported that good neurological outcome according to the POPC scale was documented in $76.7 \%$ of patients who survived to discharge. ${ }^{[42]}$

Our findings were limited by the retrospective study design, with inherent problems of selection bias, inadequate documentation and data capture resulting in potential missing data and risk of bias. The lack of a control group admitted to the PICU without prior cardiac arrest or a control group who did not survive their arrest further limits the interpretation of results. We captured data only of patients who arrived at the RCWMCH and were admitted to the PICU following successful resuscitation and ROSC. Population-based studies are necessary to determine the incidence and overall outcomes of cardiac arrests in the region.

Although we attempted, as far as possible, to report results according to the Utstein style, as recommended by paediatric studies such as that by Suominem et al., ${ }^{[27]}$ we were limited by the retrospective nature of the study and consequently poorly documented arrest circumstances. In some cases, monitoring equipment was not available at the time of the arrest and therefore some observations (e.g. arrest rhythm) were not documented and could not be fully reported on.

Notwithstanding the limitations, this study gives insight into paediatric cardiac arrest outcomes in SA, shown to be in line with those reported for a well-resourced country. ${ }^{[27]}$ Results of our study could be used as a baseline or comparator for further studies and practice improvement initiatives, ultimately to inform policy and implement targeted, optimised management of paediatric cardiac arrest.

An essential starting point for future research is the establishment of appropriate, uniform and comprehensive documentation processes for 
cardiac arrest episodes, particularly for IHCA. Development of a cardiac arrest event registry, with feedback provided to medical and nursing personnel, may help to identify those at greater risk of cardiorespiratory arrest, sensitise staff to the issues related to arrest episodes in children, and improve documentation of these events.

Patients in the wards who could potentially be at risk of cardiac arrest should be flagged as high risk, and ideally nursed in high-dependency units with appropriate monitoring, staffing and equipment in order to elicit an appropriate response in the case of a deteriorating clinical condition with the potential for cardiac arrest.

\section{Conclusion}

In this retrospective study we found the incidence of cardiac arrest with successful resuscitation and ROSC preceding PICU admission to be 2.4 per 1000 hospital admissions, with the majority occurring in children younger than 1 year. Acute respiratory failure and circulatory failure from gastrointestinal and cardiac conditions were the most common underlying causes of cardiac arrest. Children undergoing emergency endotracheal intubation constituted a notable proportion of this patient cohort. Mortality was lower than predicted in children admitted to the PICU following cardiac arrest, and the majority of survivors had normal neurological function on hospital discharge.

Acknowledgements. We thank all medical staff who contributed to the care of patients with cardiac arrest, administrative staff for making medical records available, and the Neurodevelopmental Clinic at RCWMCH, for their role in follow-up neurological testing and documentation.

Author contributions. JA was the student investigator for this study, supervised by SS, BM and AA. All investigators contributed to protocol development, data collection, analysis and interpretation, and contributed to preparing the draft of the manuscript.

Funding. None.

Conflicts of interest. None.

1. Zaritsky A, Nadkarni V, Hazinski MF, et al. Recommended guidelines for uniform reporting of pediatric advanced life support: the Pediatric Utstein Style. A statement for healthcare professionals from a task force of the American Academy of Pediatrics, the American Heart Association, and the European Resuscitation Council. Resuscitation 1995;30(2):95-115. https://doi.org/10.1016/03009572(95)00884-v

2. Kleinman ME, De Caen AR, Chameides L, et al. Part 10: Pediatric basic and advanced life support: 2010 International Consensus on Cardiopulmonary Resuscitation and Emergency Cardiovascular Care Science With Treatment Recommendations.
https://doi.org/10.1161/circulationaha.110.971093

3. Madl C, Holzer M. Brain function after resuscitation from cardiac arrest. Curr Opin Crit Care 2004;10(3):213-217. https://doi.org/10.1097/01.ccx.0000127542.32890.fa

4. Burne-Taney MJ, Kofler J, Yokota N, Weisfeldt M, Traystman RJ, Rabb H. Acute renal failure after whole body ischemia is characterized by inflammation and T cell-mediated injury. Am J Physio Renal Physiol 2003;285(1):F87-F94. https://doi.org/10.1152/ajprenal.00026.2003

5. Checchia PA, Sehra R, Moynihan J, Daher N, Tang W, Weil MH. Myocardial injury in children following resuscitation after cardiac arrest. Resuscitation 2003;57(2):131-137. https://doi. org/10.1016/s0300-9572(03)00003-0

6. Topjian AA, Nadkarni VM, Berg RA. Cardiopulmonary resuscitation in children. Curr Opin Crit Care 2009;15(3):203-208. https://doi.org/10.1097/mcc.0b013e32832931el

7. Donoghue AJ, Nadkarni V, Berg RA, et al. Out-of-hospital pediatric cardiac arrest: An epidemiologic review and assessment of current knowledge. Ann Emerg Med 2005;46(6):512-522. https://doi.org/10.1016/j.annemergmed.2005.05.028

8. Straney LD, Bray JE, Finn J, Bernard S, Pilcher D. Trends in intensive care unit cardiac arrest admissions and mortality in Australia and New Zealand. Crit Care Resusc 2014;16(2):104-111.

9. Efendijev I, Raj R, Reinikainen M, Hoppu S, Skrifvars MB. Temporal trends in cardiac arrest incidence and outcome in Finnish intensive care units from 2003 to 2013. Intensive Care Med

10. Chen J, Ou L, Hillman KM, et al. Cardiopulmonary arrest and mortality trends, and their association with rapid response system expansion. Med J Aust 2014;201(3):167-170. https://doi. org/10.5694/mja14.00019

11. Bardai A, Berdowski J, Van der Werf C, et al. Incidence, causes, and outcomes of out-ofhospital cardiac arrest in children. A comprehensive, prospective, population-based study in the hospital cardiac arrest in children. A comprehensive, prospective, population-based study in the
Netherlands. J Am Coll Cardiol 2011;57(18):1822-1828. https://doi.org/10.1016/.jacc.2010.11.054

12. Atkins DL, Everson-Stewart S, Sears GK, et al. Epidemiology and outcomes from out-of-hospital cardiac arrest in children: The Resuscitation Outcomes Consortium Epistry-Cardiac Arrest. Circulation 2009;119(11):1484-1491. https://doi.org/10.1161/circulationaha.108.802678

13. De Mos N, Van Litsenburg RR, McCrindle B, Bohn DJ, Parshuram CS. Pediatric in-intensive-care-
unit cardiac arrest: Incidence, survival, and predictive factors. Crit Care Med 2006;34(4):12091215. https://doi.org/10.1097/01.ccm.0000208440.66756.c2
14. McNally B, Robb R, Mehta M, et al. Out-of-hospital cardiac arrest surveillance - Cardiac Arrest Registry to Enhance Survival (CARES), United States, October 1, 2005 - December 31, 2010. MMWR Surveill Summ 2011;60(8):1-19.

15. Young KD, Gausche-Hill M, McClung CD, Lewis RJ. A prospective, population-based study of the epidemiology and outcome of out-of-hospital pediatric cardiopulmonary arrest. Pediatrics 2004;114(1):157-164. https://doi.org/10.1542/peds.114.1.157

16. Nitta M, Iwami T, Kitamura T, et al. Age-specific differences in outcomes after out-of-hospital cardiac arrests. Pediatrics 2011;128(4):e812-e820. https://doi.org/10.1542/peds.2010-3886

17. Nadkarni VM, Larkin GL, Peberdy MA, et al. First documented rhythm and clinical outcome from in-hospital cardiac arrest among children and adults. JAMA 2006;295(1):50-57. https://doi. org/10.1001/jama.295.1.50

18. American Heart Association. Guidelines for cardiopulmonary resuscitation and emergency cardiac care. Emergency Cardiac Care Committee and Subcommittees, American Heart Association. Part VI. Pediatric advanced life support. JAMA 1992;268(16):2262-2275. https://doi.org/10.1001/ Part VI. Pediatric advanced life

19. Kleinman ME, Chameides L, Schexnayder SM, et al. Part 14: Pediatric advanced life support 2010 American Heart Association Guidelines for Cardiopulmonary Resuscitation and Emergency Cardiovascular Care. Circulation 2010;122(18 Suppl 3):S876-S908. https://doi.org/10.1161/ CIRCULATIONAHA.110.971101

20. International Liaison Committee on Resuscitation. The International Liaison Committee on Resuscitation (ILCOR) consensus on science with treatment recommendations for pediatric and neonatal patients: Pediatric basic and advanced life support. Pediatrics 2006;117(5):e955-e977. https://doi.org/10.1542/peds.2006-0206

21. Bennett KS, Clark AE, Meert KL, et al. Early oxygenation and ventilation measurements after pediatric cardiac arrest: Lack of association with outcome. Crit Care Med 2013:41(6):1534-1542. https://doi.org/10.1097/ccm.0b013e318287f54c

22. Berg MD, Nadkarni VM, Zuercher M, Berg RA. In-hospital pediatric cardiac arrest. Pediatr Clin North Am 2008;55(3):589-604. https://doi.org/10.1016/j.pcl.2008.02.005

23. Berg RA, Sanders AB, Kern KB, et al. Adverse hemodynamic effects of interrupting ches compressions for rescue breathing during cardiopulmonary resuscitation for ventricular fibrillation cardiac arrest. Circulation 2001;104(20):2465-2470. https://doi.org/10.1161/hc4501.098926

24. Pilcher J, Weatherall M, Shirtcliffe P, Bellomo R, Young P, Beasley R. The effect of hyperoxi following cardiac arrest - a systematic review and meta-analysis of animal trials. Resuscitation following cardiac arrest $-\mathrm{a}$ systematic review and meta-analysis of
2012;83(4):417-422. https://doi.org/10.1016/.resuscitation.2011.12.021

25. Ferguson LP, Durward A, Tibby SM. Relationship between arterial partial oxygen pressure after resuscitation from cardiac arrest and mortality in children. Circulation 2012;126(3):335-342. https://doi.org/10.1161/circulationaha.111.085100

26. Nolan JP, Neumar RW, Adrie C, et al. Post-cardiac arrest syndrome: Epidemiology, pathophysiology, treatment, and prognostication. A Scientific Statement from the International Liaison Committe on Resuscitation; the American Heart Association Emergency Cardiovascular Care Committee; the Council on Cardiovascular Surgery and Anesthesia; the Council on Cardiopulmonary Perioperative, and Critical Care; the Council on Clinical Cardiology; the Council on Stroke. Resuscitation 2008;79(3):350-379. https://doi.org/10.1016/j.resuscitation.2008.09.017

27. Suominen P, Olkkola KT, Voipio V, Korpela R, Palo R, Rasanen J. Utstein style reporting of in-hospital paediatric cardiopulmonary resuscitation. Resuscitation 2000;45(1):17-25. https://doi. org/10.1016/s0300-9572(00)00167-2

28. Morrison LJ, Neumar RW, Zimmerman JL, et al. Strategies for improving survival after in-hospital cardiac arrest in the United States: 2013 consensus recommendations: A consensus statement from the American Heart Association. Circulation 2013;127(14):1538-1563. https://doi.org/10.1161 cir.0b013e31828b2770

29. Cummins RO, Chamberlain DA, Abramson NS, et al. Recommended guidelines for uniform reporting of data from out-of-hospital cardiac arrest: The Utstein style. A statement for health professionals from a task force of the American Heart Association, the European Resuscitation Council, the Heart and Stroke Foundation of Canada, and the Australian Resuscitation Council. Circulation 1991;84(2):960-975

30. Shann F, Pearson G, Slater A, Wilkinson K. Paediatric index of mortality (PIM): A mortality prediction model for children in intensive care. Intensive Care Med 1997;23(2):201-207. https:// doi.org/10.1007/s001340050317

31. McNarry AF, Goldhill DR. Simple bedside assessment of level of consciousness: Comparison of two simple assessment scales with the Glasgow Coma scale. Anaesthesia 2004;59(1):34-37. https:// doi.org/10.1111/j.1365-2044.2004.03526.x

32. Fiser DH, Long N, Roberson PK, Hefley G, Zolten K, Brodie-Fowler M. Relationship of pediatric overall performance category and pediatric cerebral performance category scores at pediatric intensive care unit discharge with outcome measures collected at hospital discharge and 1- and 6-month follow-up assessments. Crit Care Med 2000;28(7):2616-2620. https://doi. org/10.1097/00003246-200007000-00072

33. Brierley J, Carcillo JA, Choong K, et al. Clinical practice parameters for hemodynamic support of pediatric and neonatal septic shock: 2007 update from the American College of Critical Care Medicine. Crit Care Med 2009;37(2):666-688. https://doi.org/10.1097/CCM.0b013e31819323c6

34. Akcan-Arikan A, Zappitelli M, Loftis LL, Washburn KK, Jefferson LS, Goldstein SL. Modified RIFLE criteria in critically ill children with acute kidney injury. Kidney Int 2007;71(10):1028-1035. https://doi.org/10.1038/sj.ki.5002231

35. Tress EE, Kochanek PM, Saladino RA, Manole MD. Cardiac arrest in children. J Emerg Trauma Shock 2010;3(3):267-272. https://doi.org/10.4103/0974-2700.66528

36. Coté CJ. Anesthesia-related cardiac arrest in children. Anesthesiology 2001;94(5):933. http://doi. org/10.1097/00000542-200105000-00038

37. Reis AG, Nadkarni V, Perondi MB, Grisi S, Berg RA. A prospective investigation into the epidemiology of in-hospital pediatric cardiopulmonary resuscitation using the international Utstein reporting style. Pediatrics 2002;109(2):200-209. https://doi.org/10.1542/peds.109.2.200

38. Chang P, Hsu HY, Chang MH, Lin FY. Shock in the pediatric emergency service: Five years experience. Acta Paediatr Taiwan 1999;40(1):9-12.

39. Singh D, Chopra A, Pooni PA, Bhatia RC. A clinical profile of shock in children in Punjab, India. Indian Pediatr 2006;43(7):619-623.

40. Topjian AA, Berg RA, Nadkarni VM. Pediatric cardiopulmonary resuscitation: Advances in science, techniques, and outcomes. Pediatrics 2008;122(5):1086-1098. https://doi.org/10.1542/ peds.2007-3313

41. Matos RI, Watson RS, Nadkarni VM, et al. Duration of cardiopulmonary resuscitation an illness category impact survival and neurologic outcomes for in-hospital pediatric cardiac arrests. Circulation 2013;127(4):442-451. https:// doi.org/10.1161/circulationaha.112.125625

42. Meert KL, Donaldson A, Nadkarni V, et al. Multicenter cohort study of in-hospital pediatric cardiac arrest. Pediatr Crit Care Med 2009;10(5):544-553. https://doi.org/10.1097/pcc.0b013e3181a7045c

Accepted 15 October 2018. 